AP: Ontine Journat in Public Archacology Special Volume 3 - 2018 p. 153-176

\title{
Digital Remains Made Public: Sharing the Dead Online and our Future Digital Mortuary Landscape
}

Priscilla ULGUIM

Teesside University

Received: 11/09/2017 - Accepted: 30/06/2018

\begin{abstract}
We live in the information age, and our lives are increasingly digitized. Our quotidian has been transformed over the last fifty years by the adoption of innovative networking and computing technology. The digital world presents opportunities for public archaeology to engage, inform and interact with people globally. Yet, as more personal data are published online, there are growing concerns over privacy, security, and the long-term implications of sharing digital information. These concerns extend beyond the living, to the dead, and are thus important considerations for archaeologists who share the stories of past people online. This analysis argues that the 'born-digital' records of humanity may be considered as public digital mortuary landscapes, representing death, memorialization and commemoration. The potential for the analysis of digital data from these spaces could result in a phenomenon approaching immortality, whereby artificial intelligence is applied to the data of the dead. This paper investigates the ethics of a digital public archaeology of the dead while considering the future of our digital lives as mnemonic spaces, and their implications for the living.
\end{abstract}

\section{Keywords}

born digital, digital death, digital public archaeology, ethics, mortuary landscapes 


\section{Introduction}

Our self-understanding as humans is grounded in the investigation of our past, and through reflections on our present, facilitated by culture and media. As societies change and the complexity and variety of media increases, so do the ways in which we perceive the past and present. The digital revolution has led to significant cultural change within society, which can claim to have democratized the generation, distribution and interaction of digital data. The digitization, sharing and storage of data are defining features of the Information Age. People are able to disseminate vast quantities of information in an instant. Technology can reconstruct the essence of humanity using data, artificial intelligence, machine learning, robotics and 3D printing (Eden et al. 2012). However, as more personal data are shared online, there are increasing concerns over the long-term implications of data-sharing among the living. In this light, our thoughts should also extend to the dead. The implications are significant for archaeologists, since digital mnemonic mortuary landscapes have not been extensively archaeologically investigated, and ethical issues remain regarding sharing information about the dead online. Therefore, new theoretical and practical tools are required to research the dead using information that is 'borndigital'.

This article aims to link different strands of thought on the intersection of digital technology and death to provoke a critical debate on digital archaeological practice. One strand attempts to understand how digital technology is transforming the communication and visibility of death (Sofka et al. 2017; Walter 2015). Others concentrate on the use of social platforms for community engagement (Williams and Atkin 2015), while some focus more specifically on digitizing reference material for study (Digitised Diseases n.d.; British Museum 2017). To understand the range of sources, several concepts related to digital death require clarification. Firstly, the term 'digital' reflects the transformation of the physical world into binary data. I argue here that the phrase 'digital death' may relate to any aspect of death made digital. That is, the concept may encompass both the impact of death on digital assets, as well as the creation of digital assets relating to the dead. The assets include, but are not limited to, digital memorialization and the digitization of archaeological sites or human remains 
(Williams and Atkin 2015; Ulguim in press). The concept of 'borndigital death' refers to the death of those who have spent some part of their lives generating content that never existed in analogue form (content first created digitally is 'born-digital'). In contrast, those who lived and died without creating digital content are the 'analogue dead'. The deletion of digital content by living individuals removing themselves from online spaces is not considered a 'borndigital death', as the removal does not imply any actual physical death, but merely a redistribution of content (Figure 1 ). The 'borndigital death' has significant implications for archaeology, due to its impact on the record of the past. These fundamental concepts are addressed below, followed by a discussion on the ethics of digitising the analogue dead.

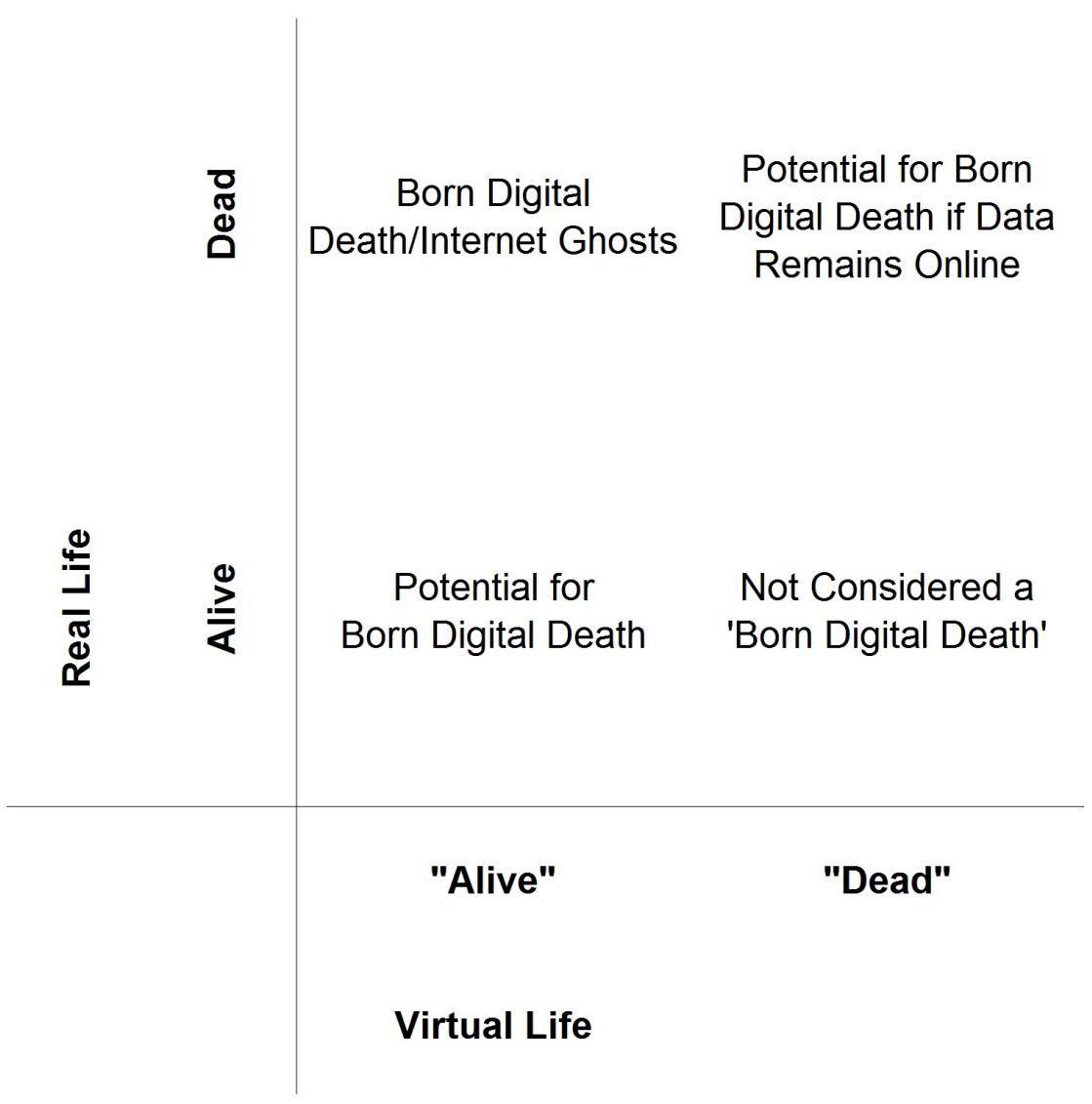

Figure 1: A matrix displaying four states of 'death' in physical and virtual life (source: after Braman et al. 2011: figure 7). 


\section{Dead mnemonic: 'born-digital death'}

'When we change the way we communicate, we change society' eloquently captures how the developments in digital communications of recent decades have revolutionized human existence (Shirkey 2008). Advances in computing and networking from the late twentieth-century onwards and the popularization of the World Wide Web enabled these transformations. As adoption of 'Web 2.0' social platforms and smartphones progressed through the hypecycle (Gartner 2017), billions began interacting online: spurring mass content generation. Social networks built a business model by digitizing real-world interactions to sell advertising, encapsulated by Facebook's 'social graph'. Hence, digital profiles became valuable assets (Leaver 2013). The outcome is a 'virtual' material culture or digital footprint of linked data including comments, likes, photos, videos, gifs, posts and emails, as well as a trail of cookies (Bowker 2007). This 'cloud' of data is linked to each user and producer and is integral to the concept of a 'born-digital death'. Furthermore, other individuals may contribute to a 'born-digital death' through post-mortem digital memorialization: creating digital presences for those who may not have created digital content during their lifetime (Hutchings 2014).

The idea of a 'born-digital death' is increasingly 'changing conceptions of hierarchy, space, privacy and property' (Gibson 2014: 221). A 'born-digital death' is a type of 'postmodern death', a public event, which is distinct from 'traditional' death within communities and 'modern' death in homes and hospitals (Walter et al. 2011). The new death combines both public and private information and audiences, creating a community of 'diverse mourners', who express 'public grief' online (Vealey 2011). Roberts (2006) found that approximately $50 \%$ of comments left in online cemetery memorial books were from strangers, and recent research into virtual church communities revealed that online groups held memorials for participants whom the congregation had never met in-person (Hutchings 2014). Online communities also stimulate physical grieving through petitions and other forms of public communication, spreading news of individuals' death to exponentially greater audiences (for example, a recent funeral in Scotland of an elderly woman with no relatives was attended by members of the community who created a Facebook page to raise awareness: BBC News 2018). 
The mix of private and public, voyeurism and immediacy in digital spaces creates issues in the 'hierarchy of grieving'. For example, the family of the deceased can be pre-empted in public announcements of family bereavements, by other people posting on social media sites (Dunn Johnson 2016). The public nature of the platforms may also encourage negative reactions (Phillips 2011). In 2006 MyDeathSpace was created to link public obituaries to the profiles of dead MySpace users, and later Perfils de Gente Morta a Brazilian group, was set up on Orkut and Facebook (Globo 2016). These groups mixed memorial and voyeuristic elements and led to inappropriate trolling on dead users' walls alongside memorials from families (Pietras 2007). Recent suicides broadcast on social media also exemplify the darker side of the web (Dasgupta 2017). Although digitizing social interactions, such as connecting with friends, sharing imagery and organizing events, was a core tenet of new digital enterprises such as Facebook, a lack of structured thought regarding management of personal data upon death caused issues (Schrage 2017). Initially, Facebook deactivated the accounts of dead users within thirty days of notification of death, but relatives or friends often did not provide notifications, content remained live and thus the accounts became 'internet ghosts' (Cann 2014) leading to distressing encounters (Brubaker et al. 2013; McCallig 2014) (Figure 2). As the logic of human mortality revealed that the population of dead users would only continue to grow on social sites (Ambrosino 2016; Hiscock 2016) concerns over privacy, security and personal data increased, controls were improved, and new fields such as 'thanatosensitivity' were developed to approach digital design with 'consideration to death' (Massimi and Charise 2009). In one case, Facebook permitted permanent memorialization of accounts following campaigns in 2007 to prevent the closure of Virginia Tech shooting victims' accounts (McCallig 2014). Commemorative pages illustrate the desire for remembrance, to ensure atrocities are recognized, and individuals are memorialized (Figure 3). While controls over data remain at the forefront of debate (Bough 2011; Oremus 2015), the discussion is framed by more fundamental tensions regarding remembering and forgetting. The inclusion of the query: 'After a person dies, what should happen to their online identity?' in Facebook's 'hard' self-imposed questions (Schrage 2017), and the recent implementation of the European Union's General Data 
Protection Regulation, to protect individual data and privacy (European Parliament 2016) exemplify some of the tensions between privacy, control and remembrance.

These examples highlight how the dead are 'more visibly present' than for much of the twentieth century (Walter 2015). Traditionally, stylized and private, informal and direct discussions with the dead now take place online in public (Brubaker and Hayes 2011 Carroll and Landry 2010; Forman et al. 2012; Kasket 2012; Kern 2013). Platforms provide a performative public space for memorialization (Veale 2004; Hess 2007), which can occur rapidly. Following a recent shooting in Parkland, Florida, USA, public memorial and support pages were set up within hours of the event (Ma and Weiss 2018). I argue that these online spaces should be considered as virtual mnemonic landscapes, which play on 'the tomb-like quality
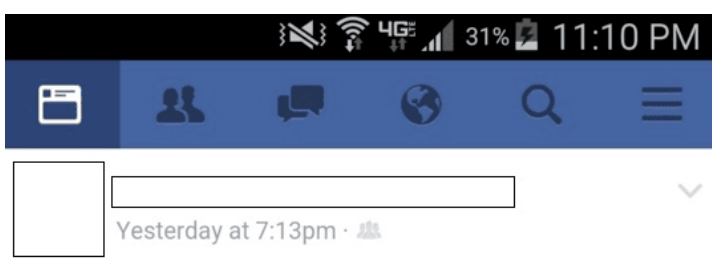

Happy Birthday $\square$ !!!! Hope you have a great day and a year filled with wonderful memories!!!

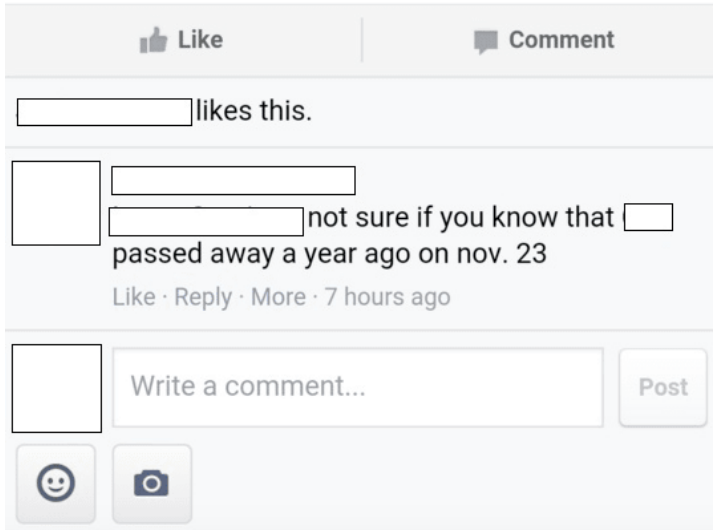

Figure 2: An example of the impact of 'live' user accounts for deceased users - a.k.a. "Internet Ghosts" http://i.imgur. com/PnOnYBp.jpg

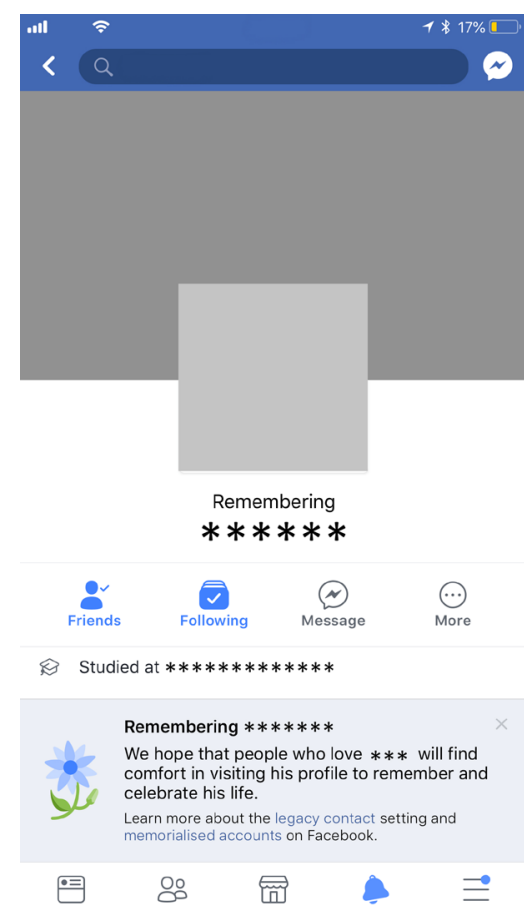

Figure 3: An example of a memorialized Facebook profile as of 2018.

Anonymized by the author. 
of the written word' (Lagerkvist 2013). They can be interpreted as "discursively built...symbols for remembrance and mourning" (Haverinen 2014), recalling physical funerary monuments which acted as 'technologies of memory' in the past (Lagerkvist 2013). Just as disasters and mass atrocities provoke and initiate large and imposing public memorials and monuments, they also provoke mass outpouring of grief and remembrance online. In parallel, individual deaths may be memorialized or commemorated more personally, in more restricted online social spaces. The construction of such digital memorial landscapes is indicative of the 'crossover between the public sphere of monument-building and private memorial practices' inherent in digital death (Renshaw 2013: 774). Agency plays an important role within these landscapes, as the interaction between agents and structure may be followed or subverted, and communication still needs to 'meet audience expectations, adapt to software and hardware limitations and comply with...companies' (Hutchings 2014). In an example from Denmark, Sørensen (2011) documents how the social norms of commemoration differ in physical cemeteries and online memorials. Although both enable the articulation of narratives, internet memorials often narrate strong personal emotions in an autobiographical format using images and textual narratives to contest social norms. In contrast, at least in the case of Danish cemeteries, even after an increase in more exuberant grave memorials, the physical spaces remain more modest in terms of personal photographic and textual narrative, even though the physical presence of graves may be richer in other aspects. However, this is one example of the variance between physical and virtual memorials and does not necessarily reflect a global phenomenon.

Although digital reactions to death take a new form and contest social norms, they follow many of the principles of the rites of passage and ritual theory (Van Gennep 1960 [1909]; Turner 1969). As such, the digital landscape of death, including online memorials, virtual cemeteries and social networks, may be assessed through the lens of funerary frameworks currently applied to physical mortuary mnemonic landscapes and monuments. Landscape approaches show how the landscape may embody memory (Holtorf 1997), such as how rune-stones might memorialize death in Scandinavian landscapes of the Viking Age (Back Danielsson 2015), or how 
landscape features could become vital parts of a memorial funerary landscape in the Neolithic (Harris 2010). Archaeologists should now dedicate time and effort to projects focused on the digital dead, to develop valuable, reusable and ethical approaches for studying online media landscapes in archaeology.

Beyond memorialization, there is a growing discourse regarding 'digital estate planning' (Carroll and Romano 2011; McCallig 2014; Sofka et al. 2017; Walker 2011). Individual digital legacies are recorded and recalled in three ways. Firstly, content from the dead is revitalized, without the necessary intention of the deceased, which result in the creation of 'digital zombies' or the 'restless dead' (Bassett 2015; Nansen et al. 2014) examples include 'performances' by Tupac Shakur, Freddie Mercury and Audrey Hepburn (Pitsillides et al. 2013; Sherlock 2013). Other deathrelated technologies, or 'thanatechnologies' (Sofka 1997), may be used to pre-record content for post-mortem release (Harvey 2017; Taubert et al. 2014). In contrast to passive born-digital data, users actively curate pre-recorded content. The most basic manage online accounts as 'digital legacies' which preserve an image of the individual post-mortem (Carroll and Romano 2011; Walker 2011), while more advanced services offer complete self-documentation (Table 1). Examples include Lifenaut (n.d.) as well as MyLifeBits, an early experiment by Microsoft Research where Gordon Bell compiled a digital archive of his life. Such services provide a form of digital 'one-way immortality' (Bell and Gray 2000; Walker 2011). The concept is a variation on 'symbolic immortality', which already exists in the form of drawings, writings and photography (Lifton 1979; Walter 2015). However, digital technology can combine data with machine learning to create virtual avatars that provide a digital 'two-way immortality' (Odom et al. 2010; Bell and Gray 2000), provoking fundamental questions about the link between the person and the physical body. Such digital immortality can render humans simply as 'a pattern of data' or 'cybersoul' (Turkle 1995; Wertheim 1999). Fictional TV series and books explore digital immortality, including Black Mirror where AI was applied to social media data of the deceased to recreate their personality (Brooker 2013), and Altered Carbon, where humans store their consciousness digitally via services which load this into different bodies. Apps already exist which can apply AI to social media or 
Table 1: 'When your heart stops beating, you'll keep tweeting', an example of a digital legacy service.

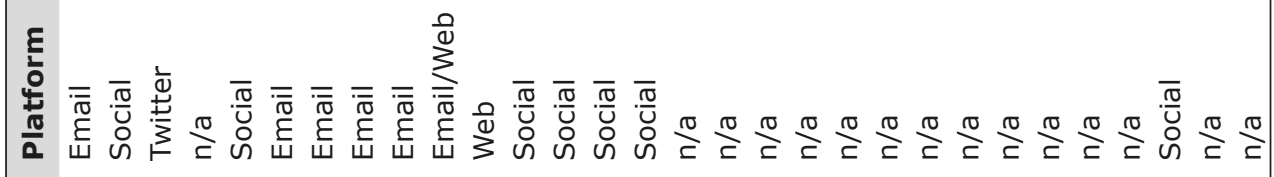

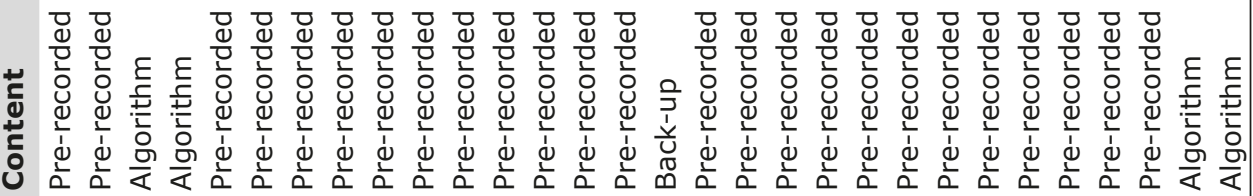

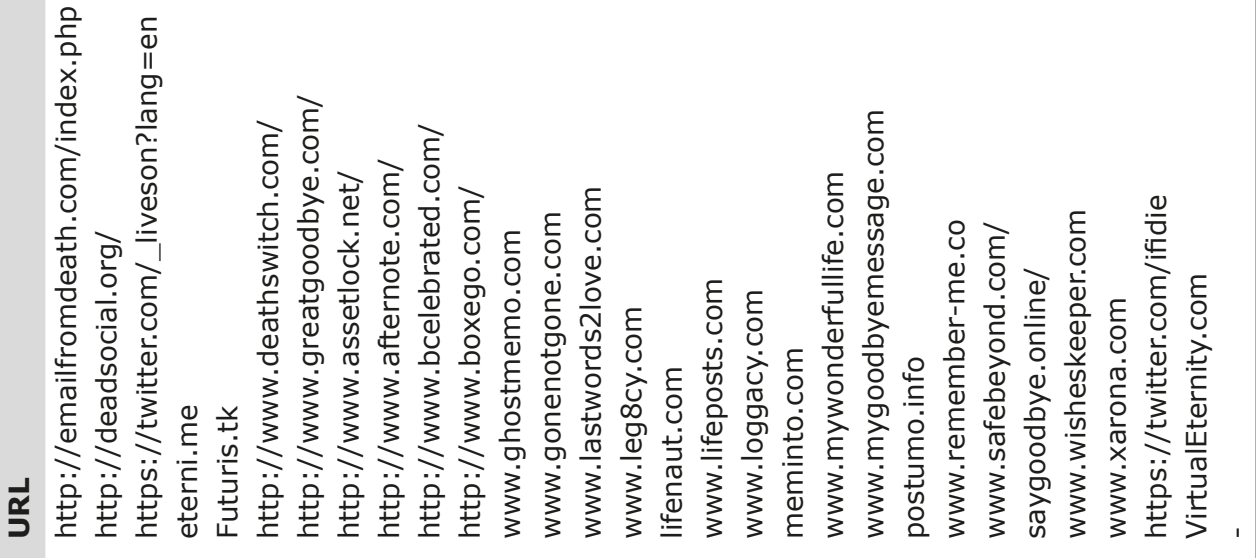

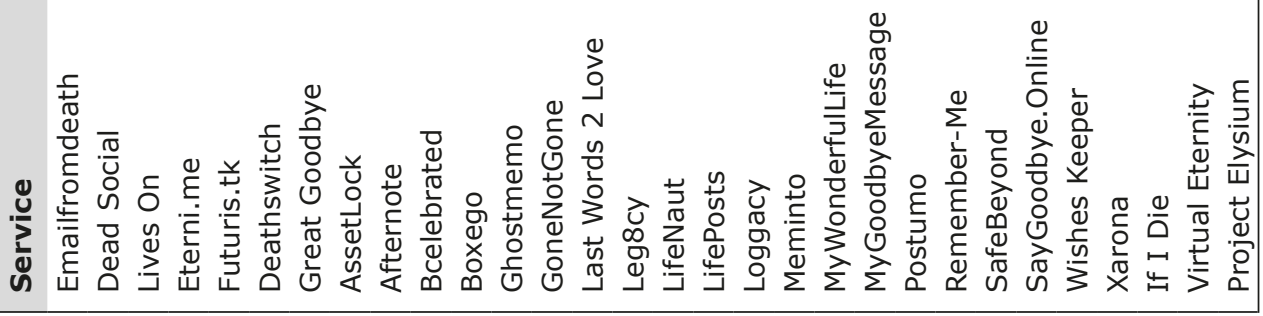


data archives to create 'chatbots' for the dead (LifeNaut n.d.; Newton 2016; Vlahos 2017). Archaeologists should consider the impact of these vast stores of data on the study of the future dead. Researchers should understand data accessibility, conservation and assess the significance of algorithmic bias to gain new insights into the lives of past peoples in the future. Beyond this, the types of self-documentation and data shared in public and personal profiles require evaluation, opening new research possibilities into an indepth understanding of public and private space and activity.

\section{Sharing the past dead online}

Beyond 'born digital death', researchers are documenting physical spaces of the dead and death online, transforming the analogue into public digital data. However, the application of digital technologies to 'analogue death' raises a series of ethical questions.

In archaeology, the term 'digital public mortuary archaeology' (DPMA), coined by Williams and Atkin (2015), refers to engagement with archaeological content concerning the dead using digital means. DPMA encompasses digital platforms for sharing content such as Digitised Diseases (n.d.), as well as blogs, vlogs and Twitter where information on mortuary archaeology is shared and discussed. Beyond these examples, crowd-sourcing platforms document cemeteries and memorials (Commonwealth War Graves Commission n.d.; Billion Graves 2017; Joods Monument 2016). The Hart Island Project (2017) uses crowd-sourcing to document unclaimed bodies in an unmarked mass grave in New York City. Another project, Facing the Nameless, creates crowd-sourced identifications of 3D scanned corpses belonging to unknown individuals, with the objective of identifying the deceased (Schneider n.d.). Such projects present the analogue dead online in an inherently public form. Within archaeology, ethical practice for the public sharing of human remains online has been subject to heated debate, for example at Higher Education Academy (HEA) events in 2013, the European Association of Archaeologists in 2015 (European Association of Archaeologists 2015) and World Archaeology Congress 8 in 2016 (World Archaeology Congress 2016; 
Hassett et al. 2016). These debates stem from the intersection of different strands of thought. The broader discussion regarding the excavation, retention, analysis and display of human remains is intrinsically linked to the investigation of people's ancestors within different cultural and historical contexts and the strong emotions embodied in the deceased (Clegg et al. 2013; Giesen et al. 2013; Parker Pearson et al. 2011). For digital archaeologists dealing with bioarchaeology, the debates have converged on how to manage digital representations of archaeological evidence ethically. Arguments have also drawn on museology, where ethical practice for physical display and storage of human remains provides a close analogue for digital representation. In both cases, clear contextualizing data with scientific justification can provide mitigation in circumstances where obtaining consent is unfeasible (Antoine 2014). However, in a recent review of bioarchaeological data shared on SketchFab, a public 3D platform, Ulguim (2018) found that many models had almost no contextualizing data: a compromising situation for the publishers and researchers working with such types of data. Furthermore, some of these 3D images had thousands of views and were available for reuse, modification and public download, meaning they could be modified, reused, or 3D printed at will. Such 'poorly documented' collections pose a threat as they have 'little value as a tool for research and educational use' (Giesen et al. 2013: 55) as well as public engagement. The low value of such collections compromises general ethical guidelines, although few directly address digital matters (BABAO 2010a; 2010b; APABE 2017; ICOM 2013). Nevertheless, archaeologists are now taking steps to define best practices and ethical guidelines for digital technology. Following the WAC8 Digital Bioarchaeology Ethics symposium, participants published a resolution that outlined principles for the ethical treatment of 'digital bioarchaeological data' (Hassett et al. 2016), furthermore the British Association for Biological Anthropology and Osteoarchaeology (BABAO) aim to introduce a set of guidelines on digital imagery and human remains. The publication of related papers will provide further insight into the debate. For example, Ulguim (2018; Figure 4) has demonstrated the requirement for the assessment of how and why dead individuals or body parts are displayed online within an ethical assessment and decision 
matrix. The variables fall into two broad categories: situational variables including consultation, local legislation, and contextual discretion; and nature-related variables: the identification and state of the individual, circumstances of death, and time since death. Data management, licencing and openness are also factors to consider. The framework also extends to the memorials and monuments of the deceased, for which modern examples have been anonymized in recent works (Sørensen 2011), while ancient or public figures may not be.

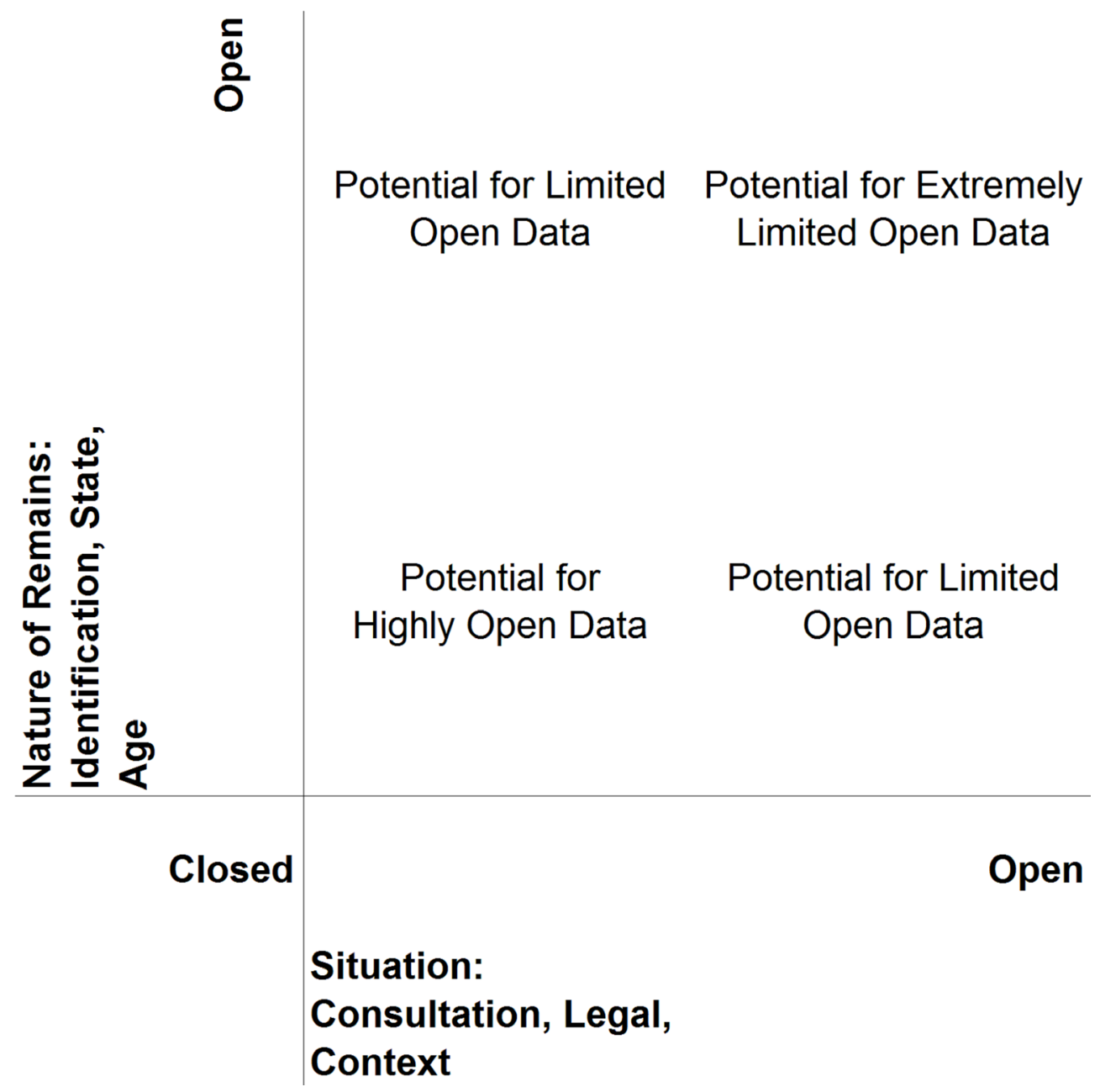

Figure 4: Ethical matrix (after Ulguim 2018: figure 14). 
These remain initial efforts which should be supported by further comprehensive works as the debate regarding balancing ethical, legal and cultural concerns evolves. Proactive, collaborative engagement and design with relevant communities around the world will only enhance these guidelines. In this light, archaeologists should acknowledge that 'there are different points of view; and, if we wish to continue...be ready to show that it [archaeology] is relevant' (Clegg et al. 2013: 162) and to balance 'public benefits of display against... feelings...of a community' (Antoine 2014: 7). In addition, research by Sayer and Walter (2016) indicates that archaeologists need to consider media coverage in public displays in order to best support ethical practices, because depiction in the media actively frames the public perception of mortuary archaeology.

\section{Implications for archaeological practice}

The emergence of the contemporary 'born-digital death' and digitization of the 'analogue dead' pose challenges and opportunities for archaeological practice. Many of these challenges remain as present as those faced by seventeenth-century antiquarians, such as Sir Thomas Browne who, 'in studying the graves, cemeteries, tombs and monuments... aspire[d] to understand the motivations and choices of these past people concerning how they use[d] material culture to commemorate the dead' (Williams 2006: 2). Likewise, in the study of digital death, archaeologists should further explore the new 'discursive' mnemonic digital landscapes of the dead and the virtual material culture of commemoration. The investigation and publication of these types of data and spaces should follow similar ethical guidelines to those now developed for the digitization of our analogue dead, namely in ensuring that affected parties are consulted. Another consideration for the archaeology of future digital content relates to the 'multiple or changing identities' adopted in online spaces (Braman et al. 2011; Wertheim 1999). The idea of 'managing' the persona that humans present to posterity is nothing new: following her death, one of Queen Victoria's daughters typed up all of her personal correspondence and burned the originals. In the same way, future archaeologists must consider that only a part of the data will be publicly archived, and even then, it will be subject to recursive behaviours of agents who conduct memorial activities, 
funerary practices and rituals, and affected by the knowledge that digital platforms are highly public spaces, where businesses enact types of 'social surveillance' (Leaver 2013). Archaeologists also face new challenges in the persistence of digital technology, data and infrastructure, exemplified by the fate of Geocities webpages post-2009 (Law and Morgan 2014) or the Internet Archive's attempts to catalogue and document the entire internet (Gotved 2014). Significant work is required to assure data preservation and conservation in the digital realm. Dealing with obsolete data storage formats is an important concern for archaeologists, especially given the likelihood that many digital services and software will be rendered obsolete after a relatively short period of time, particularly while they remain 'in the hands of powerful corporations and their decisions' (Lagerkvist 2013). Furthermore, interoperability between closed systems and standards is not always 'built-in' (Jeffrey 2012). There is also a requirement for the archaeologists of today and tomorrow to directly analyze devices and code to obtain access to information. Perry and Morgan (2015) physically 'excavated' a hard disk and highlighted a gap in the analysis of the code linking the physical disk with its virtual contents. As data becomes highly centralized and virtualized using cloud services, archaeologists may not even have access to physical machines, but rely on salvaging from data centres which service the cloud. The development of big data presents another issue, the simple question of volume. There is already a crisis of unanalysed material in store-rooms from a multitude of commercial and academic excavation projects. 'Big data' may pose just as significant a challenge (Marx 2013). One option is to apply algorithms, but these are not without their pitfalls. They are susceptible to design flaws and systematic biases, which may have ethical impacts. Furthermore, interpretation by algorithm could limit the agency of the archaeologist in investigations. Beyond these factors, relatively few guidelines have focused on the ethical questions regarding digital data for human remains, and fewer have considered in detail their digital remains. A new set of ethical principles can span both the investigation of digital data and the publication of digitized ancient remains. Recent guidance on the display of digital human remains notes that requirements for justification and consultation are just as applicable to the creation and sharing of imagery of human remains in a virtual setting 
(Ulguim 2018), and that the addition of contextualizing data is a crucial factor in mitigating ethical issues of display (Perry 2011; Williams and Atkin 2015).

Ultimately, digital death may result in a more direct discussion with the past for archaeologists through a form of digital necromancy, where artificial intelligence is applied to individuals' 'big data'. As archaeologists connect with the information of past people and places, they should remain critically aware of the impact of human agency and culture in shaping the data, as well as the imposition and influence of rapidly changing technologies upon those data. These factors fundamentally influence our discussion regarding sharing the dead online, and how archaeologists interpret digital mortuary landscapes.

\section{References}

Ambrosino, B. 2016. Facebook is a growing and unstoppable digital graveyard. BBC Future. Retrieved on 10 August 2017 from WWW http://www.bbc.com/future/story/20160313-the-unstoppablerise-of-the-facebook-dead

Antoine, D. 2014. Curating human remains in museum collections: broader considerations and a British Museum perspective. In A. Fletcher, D. Antoine, and J. D. Hill (eds), Regarding the Dead: Human Remains in the British Museum. London, The British Museum, 3-9.

APABE. 2017. Guidance for Best Practice for the Treatment of Human Remains Excavated from Christian Burial Grounds in England. Second Edition. Retrieved on 2 August 2017 from WWW http:// www.archaeologyuk.org/apabe/pdf/APABE_ToHREfCBG_FINAL_ WEB.pdf

BABAO. 2010a. Code of ethics. Retrieved on 2 August 2017 from WWW http://www.babao.org.uk/assets/Uploads-to-Web/ code-of-ethics.pdf

BABAO 2010b. Code of practice Retrieved on 2 August 2017 from WWW http://www.babao.org.uk/assets/Uploads-to-Web/codeof-practice.pdf 
BABAO. forthcoming. Digital Osteology Guideline

Back Danielsson, I-M. 2015. Walking down memory lane: runestones as mnemonic agents in the landscapes of late Viking-Age Scandinavia. In H. Williams, J. Kirton and M. Gondek (eds), Early Medieval Stone Monuments: Materiality, Biography, Landscape. Woodbridge, Boydell and Brewer, 62-86.

Bassett, D. J. 2015. Who wants to live forever? living, dying and grieving in our digital society. Social Sciences 4(4), 1127-39. DOI: $10.3390 /$ socsci4041127

BBC News. 2018. Locals unite for funeral of woman, 103, with no family. Retrieved on 22 May 2018 from WWW http://www.bbc. com/news/uk-scotland-glasgow-west-42718382

Bell, G. and Gray, J. 2000. Digital immortality. Microsoft Research. Retrieved on 2 August 2017 from WWW https://www.microsoft. com/en-us/research/wp-content/uploads/2016/02/tr-2000101.pdf

Billion Graves. 2017. Retrieved on 2 August 2017 from WWW www. BillionGraves.com

Bough, B. 2011. Digital death and digital afterlife: serious business. Forbes. Retrieved on 2 August 2017 from WWW https://www. forbes.com/sites/boninbough/2011/04/11/digital-death-anddigital-afterlife-serious-business/\#4267426a4dfe

Bowker, G. C. 2007. The past and the internet. In J. Karaganis (ed.), Structures of Participation in Digital Culture. New York, Social Science Research Council, 20-36.

Braman, J., Dudley, A. and Vincenti, G. 2011. Death, social networks and virtual worlds: a look into the digital afterlife. Ninth International Conference on Software Engineering Research, Management and Applications.

British Museum. 2017. Facing the past: the Jericho skull. British Museum. Retrieved on 20 August 2017 from WWW http://blog. britishmuseum.org/facing-the-past-the-jericho-skull/

Brooker, C. 2013. Be right back. Black Mirror. TV Series, episode aired 11 February 2013. 
Brubaker, J. R. and Hayes, G. R. 2011. 'We will never forget you [online]': An empirical investigation of post-mortem MySpace comments. Proceedings of the 2011 ACM Conference on Computer Supported Cooperative Work, CSCW 2011, Hangzhou, China, March 19-23, 2011. New York, ACM, 123-32.

Brubaker, J. R., Hayes, G. R. and Dourish, P. Beyond the grave: Facebook as a site for the expansion of death and mourning. Information Society 29,152-63.

Cann, C. K. 2014. Virtual Afterlives, Grieving the Dead in the TwentyFirst Century. Lexington, The University Press of Kentucky.

Carroll, B. and Landry, K. 2010. Logging on and letting out: using online social networks to grieve and to mourn. Bulletin of Science, Technology \& Society 30(5), 341-49.

Carroll, E. and Romano, J. 2011. Your Digital Afterlife. Berkeley, New Riders.

Commonwealth War Graves Commission n.d. Retrieved on 1 August 2017 from WWW https://www.cwgc.org/about-us

Clegg, M., Redfern, R., Bekvalac, J., and Bonney, H. 2013. Conclusions. In M. Clegg, R. Redfern, J. Beklavac and H. Bonney (eds), Global Ancestors: Understanding the Shared Humanity of Our Ancestors. Oxford, Oxbow, 162-63.

Dasgupta, R. 2017. The first social media suicide. The Guardian. Retrieved on 30 August 2017 from WWW https://www.theguardian. com/news/2017/aug/29/the-first-social-media-suicide

Digitised Diseases. n.d. Retrieved on 3 August 2017 from WWW http://www.digitiseddiseases.org

Dunn Johnson, T. 2016. STOP! Read this before you post another RIP on social media. @MrsTDJ. Retrieved on 20 August 2017 from WWW https://medium.com/@MrsTDJ/stop-read-thisbefore-you-post-another-rip-on-social-media-4c879cf69c5b

Eden, A. H., Moor, J. H., Soraker, J. H., and Steinhart, E. (eds) 2012. Singularity Hypotheses: A Scientific and Philosophical Assessment. Berlin, Springer. 
European Association of Archaeologists. 2015. EAA 2015. Retrieved on 22 May 2018 from WWW http://eaaglasgow2015.com

European Parliament. 2016. Regulation (EU) 2016/679. Retrieved on 22 May 2018 from WWW http://data.europa.eu/eli/ $\mathrm{reg} / 2016 / 679 / \mathrm{oj}$

Forman, A. E., Kern, R., and Gil-Egui, G. 2012. Death and mourning as sources of community participation in online social networks: R.I.P. pages in Facebook. First Monday 17(9). Retrieved on 15 August 2017 from WWW http://firstmonday.org/ojs/index.php/ $\mathrm{fm} /$ article/view/3935/3288

Gartner 2017. Gartner hype cycle. Retrieved on 29 July 2017 from WWW http://www.gartner.com/technology/research/ methodologies/hype-cycle.jsp

Gibson, M. 2014. Digital objects of the dead: negotiating electronic remains. In $L$ Van Brussel et al. (eds.). The Social Construction of Death. London, Palgrave Macmillan, 221-39.

Giesen, M., McCarrison, K., and Park, V. 2013. Dead and forgotten? some observations on human remains documentation in the UK. In M. Giesen (ed.), Curating Human remains: Caring for the Dead in the United Kingdom. Woodbridge, Boydell Press, 53-64.

Globo. 2016. Grupos que comentam sobre pessoas falecidas dem milhares de adeptos. O Globo. Retrieved on 25 August 2017 from WWW https://oglobo.globo.com/sociedade/gruposque-comentam-sobre-pessoas-falecidas-tem-milhares-deadeptos-20399578?

Gotved, S. 2014. Death online - alive and kicking! Thanatos 3(1), 112-26.

Harris, O. 2010. Emotional and mnemonic geographies at Hambledon Hill: texturing Neolithic places with bodies and bones. Cambridge Archaeological Journal 20, 357-71. DOI:10.1017/ S0959774310000466

Harvey, R. 2017. My digital death. BBC Radio 1 Stories. Retrieved on 20 August 2017 from WWW http://www.bbc.co.uk/iplayer/ episode/p03szcvf/radio-1-stories-my-digital-death 
Hassett, B., Rando, C., Bocaege, E., Ulguim, P. F., Wilson, A., White, S., Hirst, C., Alfonso-Durruty, M., and Smith, S. 2016. Reworded Resolution 2. WAC-8 Resolutions. Retrieved on 2 April 2017 from WWW http://worldarch.org/blog/wac-8-resolutions/

Haverinen, A. 2014. Death and mourning rituals in online environments. J@rgonia 24, 35-41.

Hiscock, M. 2016. Dead Facebook users will soon outnumber the living. The Loop. Retrieved on 20 August 2017 from http://www. theloop.ca/dead-facebook-users-will-soon-outnumber-theliving/

Holtorf, C. J. 1997. Megaliths, monumentality and memory. Archaeological Review from Cambridge 14(2), 45-66.

Hutchings, T. 2014. Death, emotion and digital media. In: Davies, Warne (eds) Emotions and Religious Dynamics. Farnham, Ashgate, 191-212.

ICOM. 2013. ICOM Code of Ethics for Museums. Paris, ICOM. Retrieved on 6 August 2017 from http://www.icom.org/ethics. html

Imgur n.d. Retrieved on 20 August 2017 from WWW http://i.imgur. com/PnOnYBp.jpg

Jeffrey, S. 2012. A new digital dark age? Collaborative web tools, social media and long-term preservation. World Archaeology 44(4), 553-70.

Joods Monument. 2016. Over dit monument. Joods Monument. Retrieved on 2 August 2017 from WWW https://www. joodsmonument. $\mathrm{nl} /$ ?lang=en

Kasket, E. 2012. Continuing bonds in the age of social networking: Facebook as a modern-day medium. Bereavement Care 31(2), 62-69.

Kern, R., Forman, E., and Gil-Egui, G. 2013. R.I.P.: Remain in perpetuity. Facebook memorial pages. Telematics and Informatics 30(1), 2-10.

Lagerkvist, A. 2013. New memory cultures and death: existential security in the digital memory ecology. Thanatos 2(2), 8-24. 
Law, M., and Morgan, C. 2014. The archaeology of digital abandonment: online sustainability and archaeological sites. Present Pasts 6(1). DOI: 10.5334/pp.58

Leaver, T. 2013. The social media contradiction: data mining and digital death. M/C Journal 16(2). Retrieved on 20 August 2017 from WWW http://journal.media-culture.org.au/index.php/ mcjournal/article/viewArticle/625

Lifenaut n.d. Retrieved on 10 August 2017 from WWW https:// www.lifenaut.com/

Lifton, R. J. 1979. The Broken Connection: On Death and the Continuity of Life. New York, Simon and Schuster.

Ma, A., and Weiss, B. 2018. These are the victims of the Florida high school shooting. Business Insider. Retrieved on 16 June 2018 from WWW http://www.businessinsider.com/floridashooting-victims-who-were-killed-injured-missing-2018-2\# benwikander-a-student-was-reportedly-shot-three-times-andtaken-into-surgery-at-a-nearby-hospital-a-family-friend-saidon-facebook-that-wikander-was-now-safe-and-sound-22

Marx, V. 2013. Biology: The big challenges of big data. Nature 498(7453), 255-60. DOI: 10.1038/498255a

Massimi, M. and Charise, A. 2009. Dying, death, and mortality: towards thanatosensitivity in HCI. In D. R. Olsen Jr, R. B. Arthur, K. Hinckley, M. R. Morris, S. E. Hudson and S. Greenberg (eds), CHI Extended Abstracts. New York, ACM, 2459-468.

McCallig, D. 2014. Facebook after death: an evolving policy in a social network. International Journal of Law and Information Technology 22(2), 107-40.

Nansen, B., Arnold, M., Gibbs, M. and Kohn, T. 2014. The restless dead in the digital cemetery. In C. M. Moreman and A. D. Lewis (eds), Digital Death: Mortality and Beyond in the Online Age. Santa Barbara, ABC-CLIO, 111-24.

Newton, C. 2016. Speak, memory. The Verge. Retrieved on 3 August 2017 from WWW https://www.theverge.com/a/lukaartificial-intelligence-memorial-roman-mazurenko-bot 
Odom, W., Harper, R., Sellen, A., Kirk, D. and Banks, R. 2010. Passing on and putting to rest: understanding bereavement in the context of interactive technologies. CHI 2010, 1831-40.

Oremus, W. 2015. Dying on Facebook just got a little less awkward. Slate. Retrieved on 2 August 2017 from WWW http://www. slate.com/blogs/future_tense/2015/02/12/facebook_legacy_ contact_who_manages_account_when_you_die.html

Parker Pearson, M., Schadla-Hall, T. and Moshenska, G. 2011. Resolving the human remains crisis in British archaeology. Papers from the Institute of Archaeology 21, 5-9. DOI: 10.5334/pia.369

Perry, S. E. 2011. Ethics and the display of human and non-human remains. Retrieved on 23 March 2016 from WWW https:// saraperry.wordpress.com/2011/12/05/ethics-and-the-displayof-human-and-non-human-remains/

Perry, S. E. and Morgan, C. L. 2015. Materializing media archaeologies: The MAD-P hard drive excavation. Journal of Contemporary Archaeology 2(1), 94-104. DOI: 10.1558/jca. v2i1.27083

Phillips, W. 2011. LOLing at tragedy: Facebook trolls, memorial pages and resistance to grief online. First Monday 16(12). Retrieved on 15 August 2017 from WWW http://firstmonday. org/ojs/index.php/fm/article/view/3168/3115

Pietras, J. 2007. The new American way of death. Salon. Retrieved on 21 August 2017 from http://www.salon.com/2007/07/31/ deathspace/

Pitsillides, S., Waller, M., and Fairfax, D. 2013. Digital death: what role does digital information play in the way we are (re)membered? In S. Warburton, and S. Hatzipanagos (eds), Digital Identity and Social Media. Hershey, Information Science Reference, 75-90.

Renshaw, L. 2013. The archaeology and material culture of modern military death. In S. Tarlow and L. Nilsson Stutz (eds), The Oxford Handbook of the Archaeology of Death and Burial. Oxford, Oxford University Press, 763-80. 
Roberts, P. 2006. From MySpace to our space: the functions of web memorials in bereavement. The Forum 32(4), 1-4.

Sayer, D. and Walter, J. 2016. Digging the dead in a digital media age. In H. Williams and M. Giles (eds.), Archaeologists and the Dead: Mortuary Archaeology and Contemporary Society. Oxford, Oxford University Press, 367-95.

Schneider, Z. n.d. Facing the nameless. Interactive Haiku. Retrieved on 3 August 2017 from WWW http://interactivehaiku.com/ facingthenameless/

Schrage, E. 2017. Introducing hard questions. Facebook Newsroom. Retrieved on 28 August 2017 from WWW https://newsroom. fb.com/news/2017/06/hard-questions/

Sherlock, A. 2013. Larger than life: digital resurrection and the re-enchantment of society. Information Society 29(3), 164-76.

Shirkey, C. 2008. Here Comes Everybody. London, Allen Lane.

Sofka, C. J. 1997. Social support 'Internetworks,' caskets for sale, and more: thanatology and the information superhighway. Death Studies 21, 553-74.

Sofka, C. J., Gibson, A., Silberman, D. R. 2017. Digital immortality or digital death? Contemplating digital end-of-life planning. In M. H. Jacobsen (ed.), Postmortal Society: Towards a Sociology of Immortality. Abingdon, Routledge, 173-96.

Sørensen, T. F. 2011. Sweet dreams: biographical blanks and the commemoration of children. Mortality 16(2), 161-75.

Taubert, M., Watts, G., Boland, J., Radbruch, L. 2014. Palliative social media. BMJ Supportive and Palliative Care 4, 13-18.

The Hart Island Project. 2017. Retrieved on 3 July 2017 from WWW https://www.hartisland.net/about

Turkle, S. 1995. Life on the Screen. London, Simon and Schuster.

Turner, V. W. 1969. The Ritual Process. London, Penguin.

Ulguim, P. F. 2018. Models and metadata: the ethics of sharing bioarchaeological 3D Data on Online Platforms. Archaeologies, DOI: https://doi.org/10.1007/s11759-018-9346-x 
Van Gennep, A. 1960 [1909]. The Rites of Passage. London, Routledge.

Veale, K. 2004. Online memorialisation: the web as a collective memorial landscape for remembering the dead. Fibreculture 3.

Vealey, K. 2011. Making dead bodies legible: Facebook's ghosts, public bodies and networked grief. Gnovis 11(2). Retrieved on 15 August 2017 from WWW http://www.gnovisjournal. org/2011/04/03/making-dead-bodies-legible/

Vlahos, J. 2017. A son's race to give his dying father artificial immortality. Wired. Retrieved on 20 August 2017 from WWW https://www.wired.com/story/a-sons-race-to-give-his-dyingfather-artificial-immortality/

World Archaeology Congress. 2016. World Archaeology Congress 8. Retrieved on 22 May 2018 from WWW http://wac8.org/ academic-program/accepted-sessions-2/ast04/

Walker, R. 2011. Cyberspace when you're dead. The New York Times Magazine. Retrieved on 13 August 2017 from WWW http://www. nytimes.com/2011/01/09/magazine/09Immortality-t.html

Walter, T. 2015. Communication media and the dead: from the Stone Age to Facebook. Mortality 20(3), 215-32.

Walter, T., Hourizi, R., Moncur, W., Pitsillides, S. 2011. Does the internet change how we die and mourn? Overview and analysis. Omega: Journal of Death \& Dying 64(4), 275-302.

Wertheim, M. 1999. The Pearly Gates of Cyberspace. London, Virago Press.

Williams, H. 2006. Death and Memory in Early Medieval Britain. Cambridge, Cambridge University Press.

Williams, H. and Atkin, A. 2015. Virtually dead: digital public mortuary archaeology. Internet Archaeology 40. https://doi. org/10.11141/ia.40.7.4 
